\title{
Novel mechanisms of central nervous system damage in HIV infection
}

\author{
This article was published in the following Dove Press journal: \\ HIVIAIDS - Research and Palliative Care \\ 10 March 2010 \\ Number of times this article has been viewed
}

\author{
Joy E Hazleton' \\ Joan W Berman ${ }^{1,2}$ \\ Eliseo A Eugenin' \\ 'Department of Pathology and \\ ${ }^{2}$ Department of Microbiology and \\ Immunology, Albert Einstein College \\ of Medicine, Bronx, NY, USA
}

\begin{abstract}
Human immunodeficiency virus-1 infection of the central nervous system is an early event after primary infection, resulting in motor and cognitive defects in a significant number of individuals despite successful antiretroviral therapy. The pathology of the infected brain is characterized by enhanced leukocyte infiltration, microglial activation and nodules, aberrant expression of inflammatory factors, neuronal dysregulation and loss, and blood-brain barrier disruption. Months to years following the primary infection, these central nervous system insults result in a spectrum of motor and cognitive dysfunction, ranging from mild impairment to frank dementia. The mechanisms that mediate impairment are still not fully defined. In this review we discuss the cellular and molecular mechanisms that facilitate impairment and new data that implicate intercellular communication systems, gap junctions and tunneling nanotubes, as mediators of human immunodeficiency virus- 1 toxicity and infection within the central nervous system. These data suggest potential targets for novel therapeutics.
\end{abstract}

Keywords: AIDS, dementia, inflammation, gap junctions, nanotubes, chemokines

\section{Introduction}

Human immunodeficiency virus-1 (HIV) infection has expanded into a global health pandemic since the first cases were described in 1981, having infected an estimated 33 million people worldwide (UNAIDS, 2008). In the early 1990s, the development of antiretroviral therapy changed the face of the disease. In the developed world, HIV went from causing a fatal disease to being a chronic infection because viral loads are frequently undetectable and CD4 counts are restored to near normal levels in most individuals on antiretroviral therapy. However, the viral reservoirs that persist in infected individuals are not eradicated and, because people live longer with HIV, the virus continues to cause damage despite low viral replication. A predominant clinical consequence of HIV that persists despite treatment is its neurological effects, which are collectively referred to as HIV-associated neurocognitive disorders (HAND) and occur in approximately $50 \%$ of infected individuals. ${ }^{1}$ Because HIV infected people on antiretroviral therapy live longer, the prevalence of cognitive and motor dysfunction is increasing. ${ }^{2,3}$ Thus, the need for effective central nervous system (CNS)-targeted therapeutics is becoming even more important. The mechanisms of HIV infection in the CNS remain incompletely characterized and it is likely that many therapeutic targets have yet to be identified.

\section{Clinical consequences of HIV infection in the CNS}

The clinical features of HAND are both subcortical and cortical, and individuals can develop cognitive impairment in a number of different domains. The clinical 
manifestations are divided into three major groups: asymptomatic neurocognitive impairment, mild neurocognitive disorder, and HIV-associated dementia. ${ }^{4}$ Asymptomatic neurocognitive impairment is defined by performance at least one standard deviation below the mean in at least two cognitive areas with no impairment in activities of daily living, mild neurocognitive disorder is performance at least one standard deviation below the mean in at least two cognitive areas with mild to moderate impairment in activities of daily living, and HIV-associated dementia is performance at least two standard deviations below the mean in at least two cognitive areas with severe impairment in activities of daily living. ${ }^{4}$ Before antiretroviral therapy, over $15 \%$ of late stage HIV-infected individuals developed HIV-associated dementia and $50 \%$ of infected individuals developed some form of HAND. ${ }^{1}$ Now, the number with HIV-associated dementia has decreased to less than $5 \%$, but the percentage of individuals with mild neurocognitive disorder has remained at $20 \%$, and the percentage with asymptomatic neurocognitive impairment has increased to $25 \%{ }^{1}$ Thus, $50 \%$ of HIV-infected individuals still develop HAND. ${ }^{1}$

HAND results in a triad of cognitive, behavioral and motor dysfunction and its progression is often not unidirectional. HIV-infected individuals may progress to asymptomatic neurocognitive impairment, then mild neurocognitive disorder, then HIV-associated dementia, but they can also fluctuate between these forms or go into remission. Diagnosis of HAND is based on neuropsychological testing, neuroimaging, and exclusion of delirium or any CNS opportunistic infections or other cause of dementia as the reason for the neurocognitive impairment., ${ }^{4,5}$ For diagnosis, neuropsychological testing must include the following domains: verbal/language, attention/working memory, abstraction/executive, memory (learning/recall), speed of information processing, sensory-perceptual, and motor skills. ${ }^{4}$ The standard of neuroimaging is magnetic resonance imaging, which demonstrates cerebral atrophy and ventricular enlargement in impaired individuals, but there is ongoing work to develop better imaging tools for diagnosis of HAND. ${ }^{5-7}$

\section{HIV neuropathology}

Soon after infection, as early as 15 days, ${ }^{8} \mathrm{HIV}$ enters the CNS in the majority of, if not all, infected individuals. Viral entry into the CNS is believed to be mediated through a "Trojan horse" mechanism, whereby HIV-infected monocytes cross the blood-brain barrier and then release virus into the CNS. HIV released from these infected cells then causes infection in the brain that results in significant inflammation and eventually neuronal damage and loss.

HIV primarily infects CNS macrophages and microglia and can infect astrocytes at low levels. ${ }^{9-13}$ There is little evidence for HIV infection of oligodendrocytes and neurons. However, significant neuronal dysfunction, including axonal and dendritic pruning, is prevalent throughout the CNS. ${ }^{14-18}$ This results from the inflammatory factors and neurotoxic substances released by infected as well as activated, uninfected cells. HAND pathology is characterized by multinucleated giant cells, microglial nodules, gliosis, myelin pallor, and neuronal loss, demonstrating the significant role of immune cells and subsequent damage to neurons in the pathogenesis of this disease.

\section{Mechanisms of HIV entry into the CNS and infection of CNS cells}

As discussed above, the predominant means of HIV entry into the CNS is through a "Trojan horse" mechanism by which infected monocytes cross the blood-brain barrier and release virus within the CNS that can then infect resident cells (Figure 1). Other proposed mechanisms include direct infection of cells that comprise the blood-brain barrier, endothelial cells and astrocytes, and transfer via these cells from the periphery to the CNS, ${ }^{19-21}$ or direct extracellular movement of the virus across a disrupted blood-brain barrier. ${ }^{22}$ While it is important to consider these mechanisms, they are less well characterized, and are likely minor contributors to CNS infection.

Under physiological conditions, leukocyte transmigration across the blood-brain barrier into the CNS parenchyma is a restricted and highly regulated process that requires cell- and tissue-specific mechanisms of leukocyteendothelial interactions. These interactions involve a variety of intracellular and extracellular molecules, including chemokines, cytokines and their receptors, cell adhesion molecules, tight junctions, and adherens junction proteins on brain microvascular endothelial cells and leukocytes. Aberrant expression of chemokines and their receptors, adhesion molecules, and matrix metalloproteinases in the context of HIV contribute to the transmigration of leukocytes across the blood-brain barrier, exacerbated CNS inflammation, and HIV replication within the brain (see Figure 1). ${ }^{22}$

Chemokines are important mediators of transmigration of leukocytes across the blood-brain barrier. Chemokines play a crucial role in the pathogenesis of HAND because they facilitate leukocyte transmigration and direct movement of resident cells, such as microglia/macrophages. Expression of chemokines and their receptors is dysregulated in HIV 
and simian immunodeficiency virus encephalitic brains in comparison with normal brains, as well as microglia/ macrophages, astrocytes, endothelial cells, and neurons exposed to HIV or soluble viral proteins. ${ }^{23-31}$ Chemokine (C-C motif) ligand 2 (CCL2) is the most potent chemoattractant chemokine for monocytes and activated T-cells. ${ }^{32-34}$ CCL2 levels are elevated in the cerebrospinal fluid and brain tissue of individuals with HIV-associated dementia. ${ }^{28}$ Our group demonstrated that CCL2 plays a major role in inflammation as well as neuroprotection (see below) in the context of HAND. CCL2 is a critical chemokine in the transmigration of HIVinfected monocytes and lymphocytes across the blood-brain barrier. ${ }^{31}$ We demonstrated that HIV infection of peripheral blood mononuclear cells (PBMCs) enhanced their transmigration across an in vitro human blood-brain barrier model in response to CCL2. ${ }^{31} \mathrm{HIV}$-infected PBMCs also had increased expression of chemokine (C-C motif) receptor 2 (CCR2), the receptor for CCL2, which may facilitate this enhanced transmigration (see Figure 1). ${ }^{31}$ The increased transmigration of PBMCs across the blood-brain barrier was associated with blood-brain barrier disruption and was CCL2 specific, given that no increased transmigration of HIV-infected cells was found with CCL3, CCL4, or CCL5. ${ }^{31}$

In addition to $\mathrm{CCR} 2$, previous reports showed enhanced expression of the chemokine receptors CXCR 4 and CCR 5 on HIV-infected T-cells, ${ }^{35,36}$ suggesting that HIV infection alters the expression of chemokine receptors to facilitate invasion as well as infection. Another chemokine, fractalkine (CX3CL1), has been associated with enhanced transendothelial migration of $\mathrm{CD} 16^{+}$monocytes under normal and inflammatory conditions and endothelial cells expressing fractalkine trigger CD16 ${ }^{+}$monocytes to produce CCL2, interleukin-6 (IL-6) and matrix metalloproteinase-9 (MMP-9). ${ }^{37,38}$ The role of fractalkine in transmigration of HIV-infected monocytes has not yet been examined.

In addition to upregulating chemokine receptors and perhaps enhancing the response to chemotactic agents, HIV infection of leukocytes also alters the expression of a number of adhesion molecules that likely facilitate transmigration of HIV-infected cells across the blood-brain barrier. It has been demonstrated in vivo that HIV infection of human monocytes increases expression of lymphocyte function-associated antigen-1 (LFA-1). ${ }^{39,40}$ HIV-infected monocytes in contact with endothelial cells induce the expression of E-selectin and vascular cell adhesion molecule-1 (VCAM-1). ${ }^{41}$ An immunohistochemical examination of HIV encephalitic tissue showed increased expression of intercellular adhesion molecule-1 (ICAM-1) and VCAM-1 on endothelial cells and astrocytes. ${ }^{42}$ We found that platelet/endothelial cell adhesion molecule-1 (PECAM-1) expression is dysregulated in HIVinfected primary human PBMCs. ${ }^{43}$ Normally, PECAM-1 is concentrated at sites of cell contact and antibodies blocking the extracellular portion of PECAM-1 selectively reduce diapedesis, but not adhesion or cell activation, of uninfected monocytes. ${ }^{44}$ Thus, homophilic interactions between PECAM-1 proteins expressed on monocytes and on endothelial cells are critical for diapedesis through interendothelial junctions. We showed that HIV-infected PBMCs shed soluble PECAM-1 (sPECAM-1) in the presence of the chemokine CCL2. ${ }^{43}$ Using post mortem tissue from individuals with HIV-associated dementia, we found an accumulation of sPECAM-1 within the CNS. ${ }^{43}$ We also showed that CCL2 increases PECAM-1 on the surface of brain microvascular endothelial cells (unpublished data from Roberts et al). Increased serum levels of sPECAM-1 were detected in individuals with multiple sclerosis and HIV, ${ }^{43,45}$ suggesting a role for the soluble form of this adhesion molecule in CNS inflammation. We propose that sPECAM-1 competes for the homotypic PECAM-1 interaction between two endothelial cells, which results in destabilization of these interactions with subsequent blood-brain barrier disruption and enhanced transmigration.

These findings support the hypothesis that HIV enters the brain by the transmigration of HIV-infected monocytes across the blood-brain barrier in response to chemokine gradients. HIV infection enhances the expression of specific chemokine receptors on the surface of infected leukocytes, enabling the detection of lower amounts of these chemokines and resulting in leukocyte activation and transmigration into the brain. HIV also increases the expression of a number of adhesion molecules, which facilitate binding and diapedesis across the blood-brain barrier.

\section{CNS damage by viral and immune factors}

While HIV is able to infect CNS macrophages, microglia, and astrocytes, as well as causing neuronal dysfunction and loss, there is little evidence to suggest that the virus infects neurons. Therefore, it is believed that infected cells release factors including viral proteins, particularly gp120 and tat, which are toxic to neurons (Figure 1).

Gp120 is the envelope surface protein of HIV and can bind CXCR4 and CCR5, even in the absence of CD4, on the surface of neurons and trigger neuronal apoptosis. ${ }^{46-48}$ The majority of brain-derived viruses are R5 (binding to CCR5), ${ }^{49}$ however, $\mathrm{X} 4$ (binding to CXCR4) viruses, which are found in the brain 


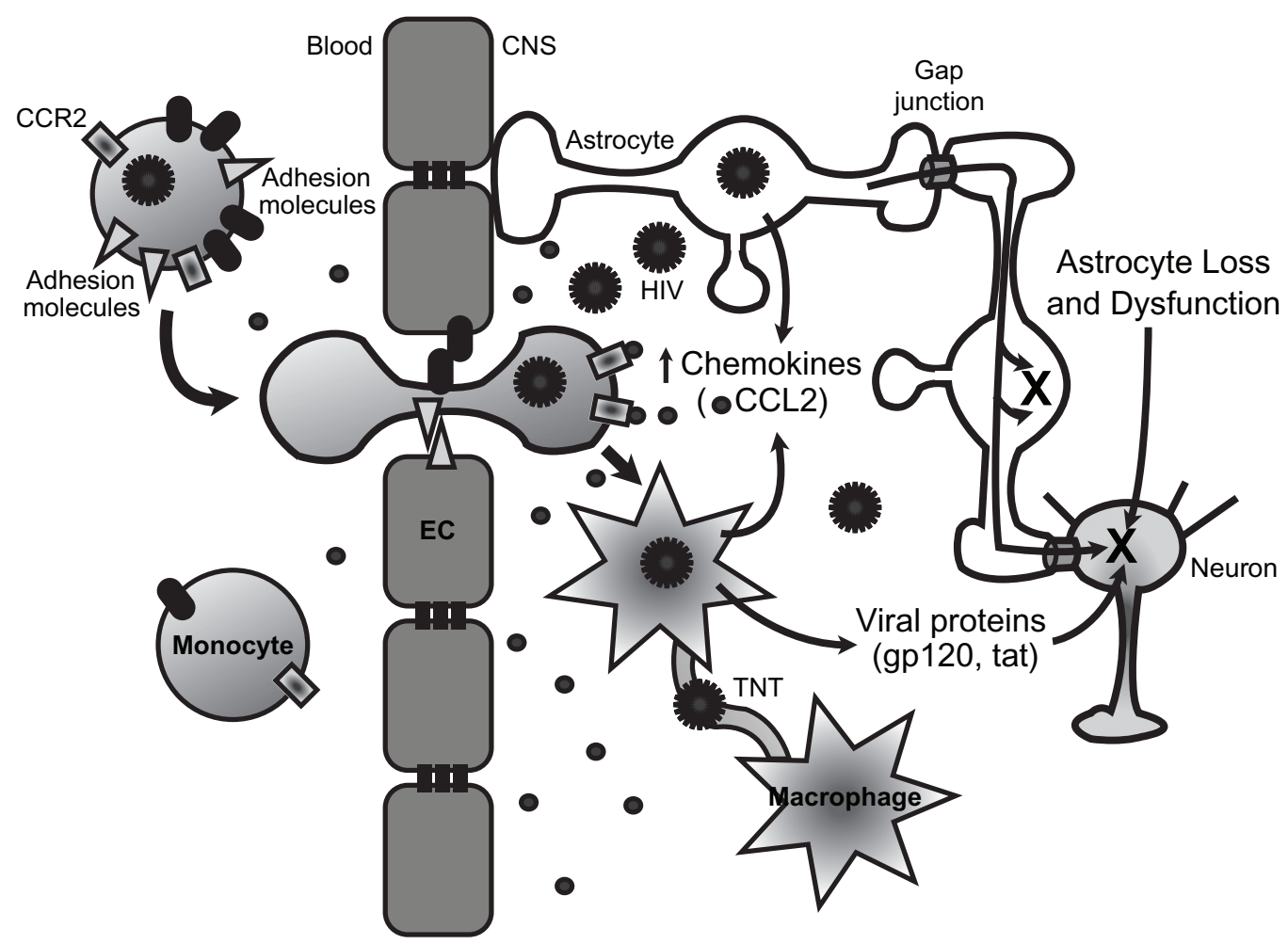

Figure I Mechanisms of HIV-mediated CNS damage. HIV infection of peripheral blood mononuclear cells, particularly monocytes, leads to enhanced expression of adhesion molecules and chemokine receptors such as CCR2. This results in increased transmigration of infected cells. HIV enters the CNS through a "Trojan horse" mechanism, crossing the blood-brain barrier, formed by endothelial cells and astrocyte end feet, within infected monocytes. Once inside the CNS, infected monocytes can differentiate into macrophages and secrete a number of inflammatory mediators, particularly chemokines such as CCL2 that further enhance transmigration of immune cells across the blood-brain barrier. HIV infection of macrophages increases the numbers of TNT that connect with other macrophages. HIV or HIV proteins may travel within or on TNT, facilitating viral spread. Infected cells also secrete viral proteins such as gp I 20 and tat that are toxic to neurons. HIV can infect astrocytes at low levels. Infected astrocytes transfer signals to neighboring uninfected astrocytes and neurons. These signals are transferred through gap junctions and result in apoptosis ( $X$ ) in both astrocytes and neurons. Astrocytes are necessary for the metabolic maintenance of neurons. Thus, the astrocyte loss and dysfunction that occurs with HIV infection also results in metabolic dysregulation and neuronal toxicity.

Abbreviations: CNS, central nervous system; EC, endothelial cells; HIV, human immunodeficiency virus; TNT, tunneling nanotubes.

late in the course of disease, or X4 gp120, induce the highest levels of neuronal cell death. ${ }^{50}$ This may contribute to the more severe forms of HAND that manifest late in disease progression. Specific mutations in the V1 and V3 gp120 loops have been identified in individuals with or without HIVassociated dementia, suggesting adaptation of the virus to the brain through changes in gp $120 .{ }^{51-53} \mathrm{Gp} 120$ can be detected in the brain of HIV-infected individuals, colocalizing with microglia/macrophages, microglial nodules, and multinucleated giant cells. ${ }^{54}$ Post-transcriptional changes in the V3 or V4 regions of gp120 that alter sequence or glycosylation may determine the course of disease as they have been correlated with the incidence of HIV-associated dementia. ${ }^{55,56}$ Treatment of macrophages or microglia with recombinant gp 120 results in the release of many cytokines and chemokines, including tumor necrosis factor- $\alpha$ (TNF- $\alpha$ ), interleukin-1 $\beta$ (IL-1 $\beta$ ), IL-6, CCL2, macrophage inflammatory proteins (MIPs), and CCL5, all of which may participate in the neuroinflammation that is also damaging to neurons. ${ }^{57-60}$
Tat, the transactivator of transcription of HIV, is released from infected cells and can be found in the serum and brain tissue of individuals with HIV encephalitis. ${ }^{61-67}$ Tat is transcribed and released from cells even when HIV replication is controlled by antiretroviral therapy because HIV integrates into the host genome. ${ }^{63}$ Tat interacts with a number of cell surface receptors, including integrins, a vascular endothelial growth factor (VEGF) receptor, and low density lipoprotein receptor-related protein-1 (LRP-1). ${ }^{68-70}$ Tat induces release of cytokines and chemokines from microglia, macrophages, neurons, and astrocytes in the CNS and causes disruption of the blood-brain barrier. ${ }^{71-73}$ In addition to these inflammatory effects, tat causes significant neurotoxicity in a variety of systems. ${ }^{74-83}$

The mechanisms that result in tat-induced neuronal apoptosis are still under investigation, but it is clear that glutamate receptors, such as the $N$-methyl-D-aspartate receptor (NMDAR), participate in the process. ${ }^{72,82-86}$ Our group demonstrated that tat treatment of mixed cultures of 
primary human fetal neurons and astrocytes causes apoptosis in both cell types. ${ }^{82,83}$ This apoptosis is mediated by early formation of a complex involving the NMDAR, LRP-1, postsynaptic density protein of $95 \mathrm{kDa}$ (PSD-95), and neuronal nitric oxide synthase. ${ }^{83}$ This complex results in activation of the NMDAR and subsequent $\mathrm{Ca}^{2+}$ influx. Increased intracellular $\mathrm{Ca}^{2+}$ activates neuronal nitric oxide synthase and results in nitric oxide production and diffusion. ${ }^{83}$ Blocking neuronal nitric oxide synthase activity inhibits apoptosis in neurons, and blocking all forms of nitric oxide synthase inhibits apoptosis in neurons and astrocytes, which suggests that nitric oxide is the key mediator of tat-induced apoptosis. ${ }^{83} \mathrm{In}$ addition, we showed that two components of the complex, NMDAR and LRP, are critical to tat-induced apoptosis. Treatment with MK801, a noncompetitive NMDAR antagonist, or with receptor associated protein (RAP), a competitive antagonist of LRP, inhibits tat-induced apoptosis in all neurons and astrocytes. ${ }^{82,83}$

LRP and its ligands, particularly apolipoprotein E4 (ApoE4), are known to be involved in Alzheimer's disease, suggesting a potential link between the mechanisms of Alzheimer's disease and HAND. Polymorphisms in ApoE4 are associated with poor prognoses in a number of neurological disorders, including Alzheimer's disease, stroke, hemorrhage, and trauma. ${ }^{87-90} \mathrm{It}$ is possible that tat toxicity and ApoE may have similar or overlapping signaling pathways involving activation of LRP, NMDAR, synaptic scaffold proteins, glutamate, and nitric oxide production. Consistent with this hypothesis, it has been demonstrated that ApoE alleles are important predictors for accelerated dementia in HIV-infected individuals and may help predict their disease course. ${ }^{91,92}$ Thus, we suggest that LRP may play a significant role in the development of HAND and may be a potential target for therapeutics.

Inflammation is a hallmark of HAND and mediates the CNS damage in neurocognitively impaired HIV-infected individuals; however, some aspects of this inflammation may actually be neuroprotective. Several inflammatory cytokines have been reported to be elevated in the CNS and/or cerebrospinal fluid of individuals with HAND, including TNF- $\alpha$, IL-1 $\beta$, IL-6, and granulocyte macrophage-colony stimulating factor. ${ }^{93-95}$ These cytokines may be produced by HIV-infected perivascular macrophages, infiltrated leukocytes, resident microglial cells, endothelial cells, and astrocytes. ${ }^{96}$ TNF- $\alpha$ upregulates HIV replication and also synergizes with IL-6 and IL-2 to cause reactivation of latent virus. ${ }^{97}$ However, TNF- $\alpha$ also appears to have neuroprotective properties by increasing NF- $\kappa \mathrm{B}$ (nuclear factor kappa-light-chain enhancer of activated B-cells) activity and altering calcium and potassium levels and bcl-2 expression. ${ }^{98}$ CCL 2 can also be neuroprotective. We showed that when mixed cultures of neurons and astrocytes were treated with tat and CCL2 concomitantly, CCL2 inhibits tat-induced apoptosis. ${ }^{82}$ When we treat with CCL2 two hours after tat, this inhibitory effect is lost, indicating that CCL2 interferes with the early effects of tat. In fact, CCL2 inhibits formation of the complex between NMDAR, LRP-1, PSD-95, and neuronal nitric oxide synthase and inhibits nitric oxide production. ${ }^{83}$ These data indicate that TNF- $\alpha$ and CCL2 have a dual role within the CNS, suggesting that the actions of these molecules depend on the time frame of their secretion and their microenvironment. Furthermore, due to this dual role, therapies targeting either molecule should be approached cautiously.

\section{Intercellular communication systems amplify CNS damage}

Our laboratory was one of the first to examine the role of intercellular communication in the context of HAND. We demonstrated that gap junctions and tunneling nanotubes (TNT) each play a role in neuroinflammation through direct transfer of mediators between the cytoplasm of connected cells. ${ }^{9,99}$

TNT and gap junctions are the only described communication systems that facilitate exchange of cytoplasmic factors through direct contact between the cytoplasm of connected cells. TNT and gap junctions coordinate important biological processes such as development, metabolism, homeostasis, and the immune response. ${ }^{100-105}$ The major difference between TNT and gap junctions is the distance between connected cells and the sizes of the molecules transferred. TNT facilitate long-range communication through extended processes, while gap junctions require direct cell-to-cell contact for their formation. Gap junctions and TNT both traffic small molecules, but gap junctions have a size limit of $1.2 \mathrm{kDa}$, while TNT can also transfer organelles and vesicles. ${ }^{101,105}$

Gap junctions are channels formed by connexins, a family of proteins with over 21 members in humans. ${ }^{106}$ Six connexins form a single connexon (hemichannel) and two connexons from apposing cells form a gap junction. ${ }^{105,107}$ Connexons can be formed by one (homotypic) or several (heterotypic) types of connexins, and gap junctions are formed by two identical (homotypic) or different (heterotypic) connexons. This variation generates connexons and gap junctions that differ in their biophysical properties and permeability. ${ }^{108}$ The pore that is formed has a large internal diameter, approximately $12 \AA$, that enables ions and intracellular messengers less than 
$1.2 \mathrm{kDa}$ to diffuse between connected cells. Molecules that are transferred through these channels include inositol triphosphate $\left(\mathrm{IP}_{3}\right)$, calcium, cyclic nucleotides, metabolites, toxic substances such as cytochrome c, neurotransmitters, and viral peptides. ${ }^{105,109}$ Through the diffusion of these second messengers, gap junctions coordinate physiological processes such as development, differentiation, neuronal synchrony, inflammation, survival, apoptosis, metabolism, cell contraction, and signaling. ${ }^{105}$ In pathologic conditions, it has been proposed that gap junctions participate in cell survival and/or apoptosis and facilitate clearance of pathogens, but the extent of gap junction involvement is not fully characterized.

We demonstrated that gap junctions in astrocytes are critical for the transfer of an apoptotic signal from HIV-infected astrocytes to uninfected astrocytes and neurons. ${ }^{9}$ Astrocytes are key cells in the CNS that regulate CNS differentiation, neuronal excitation, extracellular metabolites, synaptic plasticity, formation of scar tissue following neuronal loss, immune activation, blood-brain barrier integrity, and glycogen storage. ${ }^{110,111}$ Our data indicate that, although only a small percentage of cultured primary human fetal astrocytes are infected by HIV, these cells transmit toxic signals through gap junctions to neighboring cells, particularly uninfected astrocytes and neurons, that result in apoptosis (Figure 1). ${ }^{9}$ We also demonstrated that gap junctions control glutamate metabolism and secretion of CCL2, suggesting a critical role in maintenance of neuronal function and in CNS inflammation. ${ }^{9}$ Taken in combination, these results indicate that further investigation of HIV infection of astrocytes and its role in HAND is required despite the low level of productive infection.

We demonstrated a role for gap junctions in the transmigration of PBMCs across the blood-brain barrier. ${ }^{12}$ PBMCs normally do not express connexins. However, in inflammatory conditions, connexin 43 (Cx43) expression can be induced. ${ }^{112,113}$ Our data indicate that lipopolysaccharide (LPS) or TNF- $\alpha$ and interferon- $\gamma(\mathrm{IFN}-\gamma)$ treatment induce $\mathrm{Cx} 43$ expression in monocytes. ${ }^{12}$ These cells migrate across an in vitro model of the blood-brain barrier in response to CCL2 and we observed Cx43 staining in monocytes, astrocytes, and endothelial cells that localized to the sites of heterocellular contact. ${ }^{12}$ Gap junctions were important for the transmigration of treated monocytes because the gap junction blockers octanol and 18 - $\alpha$-glycerrhetinic acid significantly decreased transmigration. ${ }^{12}$ Based on our findings, we propose that gap junctions may play an important role in the pathogenesis of HAND by mediating infected astrocyte-induced toxicity as well as transmigration of monocytes across the blood-brain barrier.
TNT form an active communication system that enables neighboring cells to exchange organelles and vesicles, and to coordinate signaling over relatively long distances. In pathologic conditions, these cytoplasmic bridges allow bacteria and viruses to travel between connected cells without being exposed to the immune cell surfaces or extracellular antimicrobial factors. ${ }^{102-104,114-118}$ TNT formation has been described in immune cells, including B-cells, T-cells, natural killer cells, neutrophils and monocytes, as well as neuronal and glial cells. ${ }^{101}$ The mechanisms that facilitate TNT formation remain unclear, however a recent study demonstrated that a mammalian protein, $\mathrm{M}-\mathrm{Sec}$, induces formation of membrane protrusions that attach to neighboring cells and result in formation of TNT-like structures. ${ }^{119}$ Our laboratory demonstrated that primary human macrophages infected with HIV have greater numbers of TNT, suggesting that HIV induces the expression or stability of these processes. ${ }^{99}$ Furthermore, the HIV capsid protein p24 colocalizes with TNT, suggesting that viral spread may occur through this mechanism (Figure 1) ${ }^{99}$ Recently, it was demonstrated that HIV evades IgG2 and IgA responses by transferring the viral immunosuppressive protein Nef from infected macrophages to B-cells via TNT, decreasing B-cell response to $\mathrm{IgG} 2$ and IgA inducing signals from $\mathrm{CD}^{+}{ }^{+}$T-cells. ${ }^{120}$

We propose that intercellular communication mediated by gap junctions and TNT enhances cellular dysfunction and toxicity, inflammation, and HIV infection. An understanding of their role in HAND may indicate useful therapeutic targets to limit the neuropathogenesis of HIV.

\section{Potential therapeutics}

The development of successful antiretroviral therapy has significantly reduced the percentage of HIV-infected individuals who develop HIV-associated dementia; however, the percentage of individuals who are neurocognitively impaired has remained unchanged. This is due, in large part, to the fact that many of the antiretrovirals in use do not have adequate CNS penetration. Thus, although the systemic infection is well controlled, CNS infection persists. In addition to promoting an emphasis on CNS-penetrating antiretroviral therapy, a number of ongoing studies are working to develop successful adjunctive therapies to combat HAND. Some have examined ways to improve drug delivery to the CNS, including the use of nanoparticles ${ }^{121,122}$ and intranasal delivery of medications. ${ }^{123}$ Other studies have largely targeted the immune response or neuronal damage.

Oxidizing agents are a well demonstrated component of neurotoxicity and inflammation in HIV-associated CNS 
disease and a number of studies focused on using antioxidant agents to reduce neuronal damage and loss. One therapy that has been tested in clinical trials is selegiline, which inhibits monoamine oxidase $\mathrm{B}$, resulting in decreased free radicals, increased superoxide dismutase and catalase, and increasing the synthesis of neurotrophic factors. ${ }^{124-128}$ A selegiline transdermal system was developed and has been tested in a number of Phase II clinical trials. While two trials found improvement in psychomotor speed, ${ }^{129,130}$ two more recent trials did not find any difference in cognitive or functional outcome and no effect on brain metabolites or levels of markers of oxidative stress, suggesting that the selegiline transdermal system may not be clinically useful for the treatment of HAND. ${ }^{131,132}$ Another potential antioxidant therapy is a gene therapy system to deliver superoxide dismutase or glutathione peroxidase to neurons, which has been shown to decrease gp120-induced neuronal apoptosis in culture and in the caudate putamen and substantia nigra of mice. ${ }^{133-135}$ When both superoxide dismutase and glutathione peroxidase were delivered together, this also decreased tat-induced neuronal apoptosis. ${ }^{136}$

Inflammation is one of the hallmarks of HAND, and therapies to target this inflammation could potentially ameliorate the CNS consequences of HIV. Minocycline is a tetracycline derivative that has been in use since the 1960s for the treatment of bacterial infections. Minocycline can also be used for the treatment of inflammatory conditions, and recent studies showed that it can cross the blood-brain barrier and be neuroprotective. ${ }^{137-139}$ There are a number of ongoing clinical trials testing the efficacy of minocycline in the treatment of neurological diseases. In the context of HAND, minocycline was demonstrated to reduce the incidence and severity of encephalitis in simian immunodeficiency virus-infected macaques and a Phase II clinical trial is underway at the National Institute of Allergy and Infectious Diseases in the US, as well as a clinical trial in Uganda to determine whether it reduces cognitive deficits in HIV-infected individuals. ${ }^{140,141}$

Our group and others demonstrated the importance of the NMDAR in HIV-induced neurotoxicity. Memantine, a noncompetitive NMDAR antagonist, is in use in Europe for the treatment of Alzheimer's disease and Parkinson's disease and has recently been approved in the US for Alzheimer's disease treatment. ${ }^{142-147}$ Memantine prevents gp120, tat, and platelet-activating factor neurotoxicity in cell culture and is neuroprotective in mouse models of HAND. ${ }^{148-151}$ A recent Phase II clinical trial of memantine in cognitively impaired HIV-infected adults found no significant improvement in cognitive dysfunction over a period of 16 weeks, but individuals treated with memantine did have an improvement in brain metabolism, as measured by $\mathrm{N}$-acetyl aspartate to creatinine ratio using proton magnetic resonance spectroscopy. ${ }^{152}$ This study suggested that memantine may be an effective treatment for HAND, and that longer term trials are necessary to determine its efficacy.

While there are some promising therapies currently in trial targeting some of the mechanisms of HIV-mediated CNS damage discussed in this review, there is still no definitive treatment for the neurocognitive dysfunction that occurs in up to $50 \%$ of infected individuals. It is important to continue investigation of new avenues for potential therapies.

Our recent work with gap junctions and TNT suggests a role for intercellular communication in the neuropathogenesis of HIV and may provide novel targets for therapeutics. We propose that TNT may provide an alternate route for HIV spread in addition to the well characterized receptor-mediated entry. This pathway may not be affected by extracellular antiretroviral therapy and may contribute to the persistence of viral reservoirs. Thus, an understanding of the mechanisms that participate in the formation of TNT and transport of virus or viral proteins through TNT may lead to identification of therapeutic targets to block intracellular viral spread.

We also demonstrated that gap junctions facilitate transfer of an apoptotic signal from astrocytes to neighboring cells, which likely contributes to the cellular dysfunction and cell death in the CNS of HIV infected individuals. Gap junctions play vital roles in electrical and metabolic coordination within the CNS. Thus, it is unlikely that blocking gap junction channels would be a useful therapeutic approach. However, this work demonstrates the importance of the small population of infected astrocytes in the development of HAND. Thus, by understanding the mechanisms of this infection, we can begin to determine how to target this component of viral CNS infection therapeutically to eradicate this significant viral reservoir.

\section{Acknowledgements}

We are grateful to Dr. Brad Poulos and the Human Fetal Tissue Repository and the Analytical Imaging Facilities at the Albert Einstein College of Medicine. This work was supported by the National Institutes of Mental Health grants MH070297, MH075679, and MH083497 to JWB, NIH Centers for AIDS Research Grant AI-051519, a KO1 grant from the National Institutes of Mental Health (MH076679) to EAE, MSTP Training Grant 5 T32 GM007288 and the HIV-AIDS and Opportunistic Infections Institutional Training Grant T32 AI-007501 to JEH. 


\section{Disclosures}

The authors report no conflicts of interest in this work.

\section{References}

1. Ellis R, Langford D, Masliah E. HIV and antiretroviral therapy in the brain: neuronal injury and repair. Nature Reviews. 2007;8(1): 33-44.

2. Anthony IC, Ramage SN, Carnie FW, Simmonds P, Bell JE. Influence of HAART on HIV-related CNS disease and neuroinflammation. J Neuropathol Exp Neurol. 2005;64(6):529-536.

3. McArthur JC, Haughey N, Gartner S, et al. Human immunodeficiency virus-associated dementia: an evolving disease. $J$ Neurovirol. 2003;9(2):205-221.

4. Antinori A, Arendt G, Becker JT, et al. Updated research nosology for HIV-associated neurocognitive disorders. Neurology. 2007;69(18):1789-1799.

5. Ances BM, Ellis RJ. Dementia and neurocognitive disorders due to HIV-1 infection. Semin Neurol. 2007;27(1):86-92.

6. Chang L, Tomasi D, Yakupov R, et al. Adaptation of the attention network in human immunodeficiency virus brain injury. Ann Neurol. 2004;56(2):259-272.

7. Ances BM, Roc AC, Wang J, et al. Caudate blood flow and volume are reduced in HIV+ neurocognitively impaired patients. Neurology. 2006;66(6):862-866.

8. Davis LE, Hjelle BL, Miller VE, et al. Early viral brain invasion in iatrogenic human immunodeficiency virus infection. Neurology. 1992;42(9):1736-1739.

9. Eugenin EA, Berman JW. Gap junctions mediate human immunodeficiency virus-bystander killing in astrocytes. J Neurosci. 2007;27(47):12844-12850.

10. Wiley CA, Schrier RD, Nelson JA, Lampert PW, Oldstone MB. Cellular localization of human immunodeficiency virus infection within the brains of acquired immune deficiency syndrome patients. Proc Natl Acad Sci U S A. 1986;83(18):7089-7093.

11. Conant K, Tornatore C, Atwood W, Meyers K, Traub R, Major EO. In vivo and in vitro infection of the astrocyte by HIV-1. Adv Neuroimmunol. 1994;4(3):287-289.

12. Gorry PR, Ong C, Thorpe J, et al. Astrocyte infection by HIV-1: mechanisms of restricted virus replication, and role in the pathogenesis of HIV-1-associated dementia. Curr HIV Res. 2003;1(4):463-473.

13. Churchill MJ, Wesselingh SL, Cowley D, et al. Extensive astrocyte infection is prominent in human immunodeficiency virus-associated dementia. Ann Neurol. 2009;66(2):253-258.

14. James HJ, Sharer LR, Zhang Q, et al. Expression of caspase-3 in brains from paediatric patients with HIV-1 encephalitis. Neuropathol Appl Neurobiol. 1999;25(5):380-386.

15. Adle-Biassette H, Chretien F, Wingertsmann L, et al. Neuronal apoptosis does not correlate with dementia in HIV infection but is related to microglial activation and axonal damage. Neuropathol Appl Neurobiol. 1999;25(2):123-133.

16. Giometto B, An SF, Groves M, et al. Accumulation of beta-amyloid precursor protein in HIV encephalitis: relationship with neuropsychological abnormalities. Ann Neurol. 1997;42(1):34-40.

17. An SF, Giometto B, Groves M, et al. Axonal damage revealed by accumulation of beta-APP in HIV-positive individuals without AIDS. J Neuropathol Exp Neurol. 1997;56(11):1262-1268.

18. Masliah E, Heaton RK, Marcotte TD, et al. Dendritic injury is a pathological substrate for human immunodeficiency virus-related cognitive disorders. HNRC Group. The HIV Neurobehavioral Research Center. Ann Neurol. 1997;42(6):963-972.

19. Mankowski JL, Spelman JP, Ressetar HG, et al. Neurovirulent simian immunodeficiency virus replicates productively in endothelial cells of the central nervous system in vivo and in vitro. $J$ Virol. 1994;68(12):8202-8208.
20. Bobardt MD, Salmon P, Wang L, et al. Contribution of proteoglycans to human immunodeficiency virus type 1 brain invasion. $J$ Virol. 2004;78(12):6567-6584.

21. Argyris EG, Acheampong E, Nunnari G, Mukhtar M, Williams KJ, Pomerantz RJ. Human immunodeficiency virus type 1 enters primary human brain microvascular endothelial cells by a mechanism involving cell surface proteoglycans independent of lipid rafts. $J$ Virol. 2003;77(22):12140-12151.

22. Buckner CM, Luers AJ, Calderon TM, Eugenin EA, Berman JW. Neuroimmunity and the blood-brain barrier: molecular regulation of leukocyte transmigration and viral entry into the nervous system with a focus on neuroAIDS. J Neuroimmune Pharmacol. 2006;1(2):160-181.

23. Albright AV, Shieh JT, Itoh T, et al. Microglia express CCR5, CXCR4, and CCR3, but of these, CCR5 is the principal coreceptor for human immunodeficiency virus type 1 dementia isolates. $J$ Virol. 1999;73(1):205-213.

24. Lavi E, Kolson DL, Ulrich AM, Fu L, Gonzalez-Scarano F. Chemokine receptors in the human brain and their relationship to HIV infection. $J$ Neurovirol. 1998;4(3):301-311.

25. Gabuzda D, He J, Ohagen A, Vallat AV. Chemokine receptors in HIV-1 infection of the central nervous system. Semin Immunol. 1998;10(3):203-213.

26. McManus CM, Weidenheim K, Woodman SE, et al. Chemokine and chemokine-receptor expression in human glial elements: induction by the HIV protein, Tat, and chemokine autoregulation. Amer J Pathol. 2000;156(4):1441-1453.

27. Conant K, Garzino-Demo A, Nath A, et al. Induction of monocyte chemoattractant protein-1 in HIV-1 Tat-stimulated astrocytes and elevation in AIDS dementia. Proc Natl Acad Sci US A. 1998;95(6):3117-3121.

28. Kelder W, McArthur JC, Nance-Sproson T, McClernon D, Griffin DE. Beta-chemokines MCP-1 and RANTES are selectively increased in cerebrospinal fluid of patients with human immunodeficiency virusassociated dementia. Ann Neurol. 1998;44(5):831-835.

29. Sanders VJ, Pittman CA, White MG, Wang G, Wiley CA, Achim CL. Chemokines and receptors in HIV encephalitis. AIDS (London, England). 1998;12(9):1021-1026.

30. Sasseville VG, Smith MM, Mackay CR, et al. Chemokine expression in simian immunodeficiency virus-induced AIDS encephalitis. Am J Pathol. 1996;149(5):1459-1467.

31. Eugenin EA, Osiecki K, Lopez L, Goldstein H, Calderon TM, Berman JW. CCL2/monocyte chemoattractant protein-1 mediates enhanced transmigration of human immunodeficiency virus (HIV)infected leukocytes across the blood-brain barrier: a potential mechanism of HIV-CNS invasion and NeuroAIDS. J Neurosci. 2006;26(4):1098-1106.

32. Yla-Herttuala S, Lipton BA, Rosenfeld ME, et al. Expression of monocyte chemoattractant protein 1 in macrophage-rich areas of human and rabbit atherosclerotic lesions. Proc Natl Acad Sci U S A. 1991;88(12):5252-5256.

33. Sozzani S, Introna M, Bernasconi S, et al. MCP-1 and CCR2 in HIV infection: regulation of agonist and receptor expression. J Leukoc Biol. 1997;62(1):30-33.

34. Villiger PM, Terkeltaub R, Lotz M. Monocyte chemoattractant protein-1 (MCP-1) expression in human articular cartilage. Induction by peptide regulatory factors and differential effects of dexamethasone and retinoic acid. J Clin Invest. 1992;90(2):488-496.

35. Kitchen SG, Korin YD, Roth MD, Landay A, Zack JA. Costimulation of naive CD8(+) lymphocytes induces CD4 expression and allows human immunodeficiency virus type 1 infection. JVirol. 1998;72(11): 9054-9060.

36. Zloza A, Sullivan YB, Connick E, Landay AL, Al-Harthi L. CD8 ${ }^{+}$T cells that express CD4 on their surface (CD4dimCD8bright T cells) recognize an antigen-specific target, are detected in vivo, and can be productively infected by T-tropic HIV. Blood. 2003;102(6):2156-2164.

37. Ancuta P, Moses A, Gabuzda D. Transendothelial migration of CD16 $6^{+}$ monocytes in response to fractalkine under constitutive and inflammatory conditions. Immunobiology. 2004;209(1-2):11-20. 
38. Ancuta P, Wang J, Gabuzda D. CD16 $6^{+}$monocytes produce IL-6, CCL2, and matrix metalloproteinase-9 upon interaction with CX3CL1-expressing endothelial cells. J Leuko Biol. 2006;80(5):1156-1164.

39. Dhawan S, Weeks BS, Soderland C, et al. HIV-1 infection alters monocyte interactions with human microvascular endothelial cells. J Immunol. 1995;154(1):422-432.

40. Stent G, Crowe SM. Effects of HIV-1 on the surface expression of LFA-1 on cultured monocytes. J Acquir Immune Defic Syndr Hum Retrovirol. 1997;15(2):95-103.

41. Nottet HS, Persidsky Y, Sasseville VG, et al. Mechanisms for the transendothelial migration of HIV-1-infected monocytes into brain. J Immunol. 1996;156(3):1284-1295.

42. Seilhean D, Dzia-Lepfoundzou A, Sazdovitch V, et al. Astrocytic adhesion molecules are increased in HIV-1-associated cognitive/motor complex. Neuropathol Appl Neurobiol. 1997;23(2):83-92.

43. Eugenin EA, Gamss R, Buckner C, et al. Shedding of PECAM-1 during HIV infection: a potential role for soluble PECAM-1 in the pathogenesis of NeuroAIDS. J Leukoc Biol. 2006;79(3):444-452.

44. Muller WA, Weig1 SA, Deng X, Phillips DM. PECAM-1 is required for transendothelial migration of leukocytes. $J$ Exp Med. 1993;178(2):449-460.

45. Losy J, Niezgoda A, Wender M. Increased serum levels of soluble PECAM-1 in multiple sclerosis patients with brain gadoliniumenhancing lesions. J Neuroimmunol. 1999;99(2):169-172.

46. LaBranche CC, Hoffman TL, Romano J, et al. Determinants of CD4 independence for a human immunodeficiency virus type 1 variant map outside regions required for coreceptor specificity. $J$ Virol. 1999;73(12):10310-10319.

47. Aggoun-Zouaoui D, Charriaut-Marlangue C, Rivera S, Jorquera I, Ben-Ari Y, Represa A. The HIV-1 envelope protein gp120 induces neuronal apoptosis in hippocampal slices. Neuroreport. 1996;7(2): 433-436.

48. Meucci O, Miller RJ. gp120-induced neurotoxicity in hippocampal pyramidal neuron cultures: protective action of TGF-beta1. J Neurosci. 1996;16(13):4080-4088.

49. Ohagen A, Devitt A, Kunstman KJ, et al. Genetic and functional analysis of full-length human immunodeficiency virus type 1 env genes derived from brain and blood of patients with AIDS. Journal Virol. 2003;77(22):12336-12345.

50. Ohagen A, Ghosh S, He J, et al. Apoptosis induced by infection of primary brain cultures with diverse human immunodeficiency virus type 1 isolates: evidence for a role of the envelope. J Virol. 1999;73(2):897-906.

51. Power C, McArthur JC, Johnson RT, et al. Demented and nondemented patients with AIDS differ in brain-derived human immunodeficiency virus type 1 envelope sequences. J Virol. 1994;68(7):4643-4649.

52. Power C, McArthur JC, Nath A, et al. Neuronal death induced by brain-derived human immunodeficiency virus type 1 envelope genes differs between demented and nondemented AIDS patients. J Virol. 1998;72(11):9045-9053.

53. Van Marle G, Rourke SB, Zhang K, et al. HIV dementia patients exhibit reduced viral neutralization and increased envelope sequence diversity in blood and brain. AIDS (London, England). 2002;16(14):1905-1914.

54. Jones MV, Bell JE, Nath A. Immunolocalization of HIV envelope gp120 in HIV encephalitis with dementia. AIDS (London, England). 2000;14(17):2709-2713.

55. Gorry PR, Dunfee RL, Mefford ME, et al. Changes in the V3 region of gp120 contribute to unusually broad coreceptor usage of an HIV-1 isolate from a CCR5 Delta32 heterozygote. Virology. 2007;362(1):163-178.

56. Dunfee RL, Thomas ER, Wang J, Kunstman K, Wolinsky SM, Gabuzda D. Loss of the N-linked glycosylation site at position 386 in the HIV envelope V4 region enhances macrophage tropism and is associated with dementia. Virology. 2007;367(1):222-234.

57. Corasaniti MT, Bagetta G, Rotiroti D, Nistico G. The HIV envelope protein gp120 in the nervous system: interactions with nitric oxide, interleukin-1beta and nerve growth factor signalling, with pathological implications in vivo and in vitro. Biochem Pharmacol. 1998;56(2): $153-156$
58. Lee C, Tomkowicz B, Freedman BD, Collman RG. HIV-1 gp120-induced TNF- $\{$ alpha $\}$ production by primary human macrophages is mediated by phosphatidylinositol-3 (PI-3) kinase and mitogen-activated protein (MAP) kinase pathways. J Leukoc Biol. 2005;78(4):1016-1023.

59. Fantuzzi L, Canini I, Belardelli F, Gessani S. HIV-1 gp120 stimulates the production of beta-chemokines in human peripheral blood monocytes through a CD4-independent mechanism. J Immunol. 2001;166(9): 5381-5387.

60. D'Aversa TG, Eugenin EA, Berman JW. NeuroAIDS: contributions of the human immunodeficiency virus-1 proteins Tat and gp120 as well as CD40 to microglial activation. J Neurosci Res. 2005;81(3):436-446.

61. Chang HC, Samaniego F, Nair BC, Buonaguro L, Ensoli B. HIV-1 Tat protein exits from cells via a leaderless secretory pathway and binds to extracellular matrix-associated heparan sulfate proteoglycans through its basic region. AIDS (London, England). 1997;11(12):1421-1431.

62. Ensoli B, Barillari G, Salahuddin SZ, Gallo RC, Wong-Staal F. Tat protein of HIV-1 stimulates growth of cells derived from Kaposi's sarcoma lesions of AIDS patients. Nature. 1990;345(6270):84-86.

63. Ensoli B, Buonaguro L, Barillari G, et al. Release, uptake, and effects of extracellular human immunodeficiency virus type 1 Tat protein on cell growth and viral transactivation. J Virol. 1993;67(1):277-287.

64. Frankel AD, Pabo CO. Cellular uptake of the tat protein from human immunodeficiency virus. Cell. 1988;55(6):1189-1193.

65. Hudson L, Liu J, Nath A, et al. Detection of the human immunodeficiency virus regulatory protein tat in CNS tissues. $J$ Neurovirol. 2000;6(2):145-155.

66. Wieland U, Kuhn JE, Jassoy C, Rubsamen-Waigmann H, Wolber V, Braun RW. Antibodies to recombinant HIV-1 vif, tat, and nef proteins in human sera. Med Microbiol Immunol. 1990;179(1):1-11.

67. Westendorp MO, Frank R, Ochsenbauer C, et al. Sensitization of $\mathrm{T}$ cells to CD95-mediated apoptosis by HIV-1 Tat and gp120. Nature. 1995;375(6531):497-500.

68. Vogel BE, Lee SJ, Hildebrand A, et al. A novel integrin specificity exemplified by binding of the alpha $\mathrm{v}$ beta 5 integrin to the basic domain of the HIV Tat protein and vitronectin. J Cell Biol. 1993;121(2):461-468.

69. Albini A, Soldi R, Giunciuglio D, et al. The angiogenesis induced by HIV-1 tat protein is mediated by the Flk-1/KDR receptor on vascular endothelial cells. Nat Med. 1996;2(12):1371-1375.

70. Liu Y, Jones M, Hingtgen CM, et al. Uptake of HIV-1 tat protein mediated by low-density lipoprotein receptor-related protein disrupts the neuronal metabolic balance of the receptor ligands. Nat Med. 2000;6(12):1380-1387.

71. Pu H, Tian J, Flora G, et al. HIV-1 Tat protein upregulates inflammatory mediators and induces monocyte invasion into the brain. Mol Cell Neurosci. 2003;24(1):224-237.

72. King JE, Eugenin EA, Buckner CM, Berman JW. HIV tat and neurotoxicity. Microbes Infect. 2006;8(5):1347-1357.

73. Rappaport J, Joseph J, Croul S, et al. Molecular pathway involved in HIV-1-induced CNS pathology: role of viral regulatory protein, Tat. J Leukoc Biol. 1999;65(4):458-465.

74. Jones M, Olafson K, Del Bigio MR, Peeling J, Nath A. Intraventricular injection of human immunodeficiency virus type 1 (HIV-1) tat protein causes inflammation, gliosis, apoptosis, and ventricular enlargement. J Neuropathol Exp Neurol. 1998;57(6):563-570.

75. Magnuson DS, Knudsen BE, Geiger JD, Brownstone RM, Nath A. Human immunodeficiency virus type 1 tat activates non-N-methyl-Daspartate excitatory amino acid receptors and causes neurotoxicity. Ann Neurol. 1995;37(3):373-380.

76. Nath A, Psooy K, Martin C, et al. Identification of a human immunodeficiency virus type 1 Tat epitope that is neuroexcitatory and neurotoxic. J Virol. 1996;70(3):1475-1480.

77. New DR, Ma M, Epstein LG, Nath A, Gelbard HA. Human immunodeficiency virus type 1 Tat protein induces death by apoptosis in primary human neuron cultures. J Neurovirol. 1997;3(2):168-173.

78. Sabatier JM, Vives E, Mabrouk K, et al. Evidence for neurotoxic activity of tat from human immunodeficiency virus type 1. J Virol. 1991;65(2):961-967. 
79. Shi B, Raina J, Lorenzo A, Busciglio J, Gabuzda D. Neuronal apoptosis induced by HIV-1 Tat protein and TNF-alpha: potentiation of neurotoxicity mediated by oxidative stress and implications for HIV-1 dementia. J Neurovirol. 1998;4(3):281-290.

80. Strijbos PJ, Zamani MR, Rothwell NJ, Arbuthnott G, Harkiss G. Neurotoxic mechanisms of transactivating protein Tat of Maedi-Visna virus. Neurosci Lett. 1995;197(3):215-218.

81. Weeks BS, Lieberman DM, Johnson B, et al. Neurotoxicity of the human immunodeficiency virus type 1 tat transactivator to PC12 cells requires the Tat amino acid 49-58 basic domain. J Neurosci Res. 1995;42(1):34-40.

82. Eugenin EA, D’Aversa TG, Lopez L, Calderon TM, Berman JW. MCP-1 (CCL2) protects human neurons and astrocytes from NMDA or HIV-tat-induced apoptosis. J Neurochem. 2003;85(5):1299-1311.

83. Eugenin EA, King JE, Nath A, et al. HIV-tat induces formation of an LRP-PSD-95- NMDAR-nNOS complex that promotes apoptosis in neurons and astrocytes. Proc Natl Acad Sci U S A. 2007;104(9): 3438-3443.

84. Wang P, Barks JD, Silverstein FS. Tat, a human immunodeficiency virus-1-derived protein, augments excitotoxic hippocampal injury in neonatal rats. Neuroscience. 1999;88(2):585-597.

85. Haughey NJ, Nath A, Mattson MP, Slevin JT, Geiger JD. HIV-1 Tat through phosphorylation of NMDA receptors potentiates glutamate excitotoxicity. J Neurochem. 2001;78(3):457-467.

86. Bonavia R, Bajetto A, Barbero S, Albini A, Noonan DM, Schettini G. HIV-1 Tat causes apoptotic death and calcium homeostasis alterations in rat neurons. Biochem Biophys Res Commun. 2001;288(2): 301-308.

87. Strittmatter WJ, Saunders AM, Schmechel D, et al. Apolipoprotein E: high-avidity binding to beta-amyloid and increased frequency of type 4 allele in late-onset familial Alzheimer disease. Proc Natl Acad Sci U S A. 1993;90(5):1977-1981.

88. Slooter AJ, Tang MX, van Duijn CM, et al. Apolipoprotein E epsilon4 and the risk of dementia with stroke. A population-based investigation. J Amer Med Assoc. 1997;277(10):818-821.

89. Alberts MJ, Graffagnino C, McClenny C, et al. ApoE genotype and survival from intracerebral haemorrhage. Lancet. 1995; 346(8974):575.

90. Tardiff BE, Newman MF, Saunders AM, et al. Preliminary report of a genetic basis for cognitive decline after cardiac operations. The Neurologic Outcome Research Group of the Duke Heart Center. Ann Thorac Surg. 1997;64(3):715-720.

91. Corder EH, Lannfelt L, Bogdanovic N, Fratiglioni L, Mori H. The role of APOE polymorphisms in late-onset dementias. Cell Mol Life Sci. 1998;54(9):928-934.

92. Burt TD, Agan BK, Marconi VC, et al. Apolipoprotein (apo) E4 enhances HIV-1 cell entry in vitro, and the APOE epsilon4/epsilon4 genotype accelerates HIV disease progression. Proc Natl Acad Sci U S A. 2008;105(25):8718-8723.

93. Sharief MK, Ciardi M, Thompson EJ, et al. Tumour necrosis factoralpha mediates blood-brain barrier damage in HIV-1 infection of the central nervous system. Mediators Inflamm. 1992;1(3):191-196.

94. Achim CL, Heyes MP, Wiley CA. Quantitation of human immunodeficiency virus, immune activation factors, and quinolinic acid in AIDS brains. J Clin Invest. 1993;91(6):2769-2775.

95. Perrella O, Guerriero M, Izzo E, Soscia M, Carrieri PB. Interleukin-6 and granulocyte macrophage-CSF in the cerebrospinal fluid from HIV infected subjects with involvement of the central nervous system. Arquivos de neuro-psiquiatria. 1992;50(2):180-182.

96. Gonzalez-Scarano F, Martin-Garcia J. The neuropathogenesis of AIDS. Nat Rev Immunol. 2005;5(1):69-81.

97. Chun TW, Engel D, Mizell SB, Ehler LA, Fauci AS. Induction of HIV1 replication in latently infected $\mathrm{CD}^{+} \mathrm{T}$ cells using a combination of cytokines. J Exp Med. 1998;188(1):83-91.

98. Sriram K, O’Callaghan JP. Divergent roles for tumor necrosis factor-alpha in the brain. J Neuroimmune Pharmacol. 2007;2(2): $140-153$.
99. Eugenin EA, Gaskill PJ, Berman JW. Tunneling nanotubes (TNT) are induced by HIV-infection of macrophages: a potential mechanism for intercellular HIV trafficking. Cell Immunol. 2009;254(2):142-148.

100. Eugenin EA, Gaskill PJ, Berman JW. Tunneling nanotubes (TNT): A potential mechanism for intercellular HIV trafficking. Communicative and Integrative Biology. 2009;2(3):243-244.

101. Gerdes HH, Bukoreshtliev NV, Barroso JF. Tunneling nanotubes: a new route for the exchange of components between animal cells. FEBS Letters. 2007;581(11):2194-2201.

102. Onfelt B, Davis DM. Can membrane nanotubes facilitate communication between immune cells? Biochem Soc Trans. 2004;32(Pt 5): 676-678.

103. Onfelt B, Purbhoo MA, Nedvetzki S, Sowinski S, Davis DM. Longdistance calls between cells connected by tunneling nanotubules. Sci STKE. 2005;2005(313):pe55.

104. Rustom A, Saffrich R, Markovic I, Walther P, Gerdes HH. Nanotubular highways for intercellular organelle transport. Science (New York, N.) 2004;303(5660):1007-1010.

105. Saez JC, Berthoud VM, Branes MC, Martinez AD, Beyer EC. Plasma membrane channels formed by connexins: their regulation and functions. Physiol Rev. 2003;83(4):1359-1400.

106. Willecke K, Eiberger J, Degen J, et al. Structural and functional diversity of connexin genes in the mouse and human genome. Biol Chem. 2002;383(5):725-737.

107. Bennett MV, Rubin JB, Bargiello TA, Verselis VK. Structure-function studies of voltage sensitivity of connexins, the family of gap junction forming proteins. Jpn J Physiol. 1993;43 Suppl 1:S301-S310.

108. Harris AL, Bevans CG. Exploring hemichannel permeability in vitro. Methods Mol Biol. 2001;154:357-377.

109. Bennett MV, Zukin RS. Electrical coupling and neuronal synchronization in the Mammalian brain. Neuron. 2004;41(4):495-511.

110. Rouach N, Avignone E, Meme W, et al. Gap junctions and connexin expression in the normal and pathological central nervous system. Biol Cell. 2002;94(7-8):457-475.

111. Kielian T, Esen N. Effects of neuroinflammation on glia-glia gap junctional intercellular communication: a perspective. Neurochem Int. 2004;45(2-3):429-436.

112. Eugenin EA, Branes MC, Berman JW, Saez JC. TNF-alpha plus IFNgamma induce connexin 43 expression and formation of gap junctions between human monocytes/macrophages that enhance physiological responses. J Immunol. 2003;170(3):1320-1328.

113. El-Sabban ME, Merhi RA, Haidar HA, et al. Human T-cell lymphotropic virus type 1-transformed cells induce angiogenesis and establish functional gap junctions with endothelial cells. Blood. 2002;99(9):3383-3389.

114. Onfelt B, Nedvetzki S, Benninger RK, et al. Structurally distinct membrane nanotubes between human macrophages support long-distance vesicular traffic or surfing of bacteria. J Immunol. 2006;177(12): 8476-8483.

115. Onfelt B, Nedvetzki S, Yanagi K, Davis DM. Cutting edge: Membrane nanotubes connect immune cells. J Immunol. 2004;173(3): 1511-1513.

116. Magalhaes AC, Baron GS, Lee KS, et al. Uptake and neuritic transport of scrapie prion protein coincident with infection of neuronal cells. J Neurosci. 2005;25(21):5207-5216.

117. Watkins SC, Salter RD. Functional connectivity between immune cells mediated by tunneling nanotubules. Immunity. 2005;23(3):309-318.

118. Sherer NM, Lehmann MJ, Jimenez-Soto LF, Horensavitz C, Pypaert M, Mothes W. Retroviruses can establish filopodial bridges for efficient cell-to-cell transmission. Nat Cell Biol. 2007;9(3):310-315.

119. Hase K, Kimura S, Takatsu H, et al. M-Sec promotes membrane nanotube formation by interacting with Ral and the exocyst complex. Nat Cell Biol. 2009;11(12):1427-1432.

120. Xu W, Santini PA, Sullivan JS, et al. HIV-1 evades virus-specific IgG2 and IgA responses by targeting systemic and intestinal B cells via long-range intercellular conduits. Nat Immunol. 2009;10(9): 1008-1017. 
121. Dou H, Grotepas CB, McMillan JM, et al. Macrophage delivery of nanoformulated antiretroviral drug to the brain in a murine model of neuroAIDS. J Immunol. 2009;183(1):661-669.

122. Dou H, Morehead J, Destache CJ, et al. Laboratory investigations for the morphologic, pharmacokinetic, and anti-retroviral properties of indinavir nanoparticles in human monocyte-derived macrophages. Virology. 2007;358(1):148-158.

123. Hanson LR, Frey WH 2nd. Strategies for intranasal delivery of therapeutics for the prevention and treatment of neuroAIDS. J Neuroimmune Pharmacol. 2007;2(1):81-86.

124. Ansari KS, Yu PH, Kruck TP, Tatton WG. Rescue of axotomized immature rat facial motoneurons by R(-)-deprenyl: stereospecificity and independence from monoamine oxidase inhibition. $J$ Neurosci. 1993;13(9):4042-4053.

125. Carrillo MC, Kitani K, Kanai S, Sato Y, Miyasaka K, Ivy GO. (-) Deprenyl increases activities of superoxide dismutase and catalase in certain brain regions in old male mice. Life Sci. 1994;54(14):975-981.

126. Matsui Y, Kumagae Y. Monoamine oxidase inhibitors prevent striatal neuronal necrosis induced by transient forebrain ischemia. Neurosci Lett. 1991;126(2):175-178.

127. Salo PT, Tatton WG. Deprenyl reduces the death of motoneurons caused by axotomy. J Neurosci Res. 1992;31(2):394-400.

128. Tatton WG, Greenwood CE. Rescue of dying neurons: a new action for deprenyl in MPTP parkinsonism. J Neurosci Res. 1991;30(4): 666-672.

129. A randomized, double-blind, placebo-controlled trial of deprenyl and thioctic acid in human immunodeficiency virus-associated cognitive impairment. Dana Consortium on the Therapy of HIV Dementia and Related Cognitive Disorders. Neurology. 1998;50(3):645-651.

130. Sacktor N, Schifitto G, McDermott MP, Marder K, McArthur JC, Kieburtz K. Transdermal selegiline in HIV-associated cognitive impairment: pilot, placebo-controlled study. Neurology. 2000;54(1): 233-235.

131. Schifitto G, Yiannoutsos CT, Ernst T, et al. Selegiline and oxidative stress in HIV-associated cognitive impairment. Neurology. 2009.

132. Schifitto G, Zhang J, Evans SR, et al. A multicenter trial of selegiline transdermal system for HIV-associated cognitive impairment. Neurology. 2007;69(13):1314-1321.

133. Agrawal L, Louboutin JP, Reyes BA, Van Bockstaele EJ, Strayer DS. Antioxidant enzyme gene delivery to protect from HIV-1 gp120induced neuronal apoptosis. Gene Ther. 2006;13(23):1645-1656.

134. Louboutin JP, Agrawal L, Reyes BA, Van Bockstaele EJ, Strayer DS. Protecting neurons from HIV-1 gp120-induced oxidant stress using both localized intracerebral and generalized intraventricular administration of antioxidant enzymes delivered by SV40-derived vectors. Gene Ther. 2007;14(23):1650-1661.

135. Louboutin JP, Agrawal L, Reyes BA, Van Bockstaele EJ, Strayer DS. HIV-1 gp120 neurotoxicity proximally and at a distance from the point of exposure: protection by rSV40 delivery of antioxidant enzymes. Neurobiol Dis. 2009;34(3):462-476.

136. Agrawal L, Louboutin JP, Strayer DS. Preventing HIV-1 Tat-induced neuronal apoptosis using antioxidant enzymes: mechanistic and therapeutic implications. Virology. 2007;363(2):462-472.
137. Sapadin AN, Fleischmajer R. Tetracyclines: nonantibiotic properties and their clinical implications. J Am Acad Dermatol. 2006;54(2): 258-265.

138. Elewa HF, Hilali H, Hess DC, Machado LS, Fagan SC. Minocycline for short-term neuroprotection. Pharmacotherapy. 2006;26(4):515-521.

139. Stirling DP, Koochesfahani KM, Steeves JD, Tetzlaff W. Minocycline as a neuroprotective agent. Neuroscientist. 2005;11(4):308-322.

140. Follstaedt SC, Barber SA, Zink MC. Mechanisms of minocyclineinduced suppression of simian immunodeficiency virus encephalitis: inhibition of apoptosis signal-regulating kinase 1. J Neurovirol. 2008;14(5):376-388.

141. Zink MC, Uhrlaub J, DeWitt J, et al. Neuroprotective and anti-human immunodeficiency virus activity of minocycline. J Amer Med Assoc. 2005;293(16):2003-2011.

142. Lipton SA. Paradigm shift in neuroprotection by NMDA receptor blockade: memantine and beyond. Nat Rev Drug Discov. 2006;5(2):160-170.

143. Fleischhacker WW, Buchgeher A, Schubert H. Memantine in the treatment of senile dementia of the Alzheimer type. Prog Neuropsychopharmacol Biol Psychiatry. 1986;10(1):87-93.

144. Winblad B, Poritis N. Memantine in severe dementia: results of the 9M-Best Study (Benefit and efficacy in severely demented patients during treatment with memantine). Int $J$ Geriatr Psych. 1999;14(2):135-146

145. Rabey JM, Nissipeanu P, Korczyn AD. Efficacy of memantine, an NMDA receptor antagonist, in the treatment of Parkinson's disease. J Neural Transm. 1992;4:277-282.

146. Reisberg B, Doody R, Stoffler A, Schmitt F, Ferris S, Mobius HJ. Memantine in moderate-to-severe Alzheimer's disease. New Engl J Med. 2003;348(14):1333-1341.

147. Tariot PN, Farlow MR, Grossberg GT, Graham SM, McDonald S, Gergel I. Memantine treatment in patients with moderate to severe Alzheimer disease already receiving donepezil: a randomized controlled trial. J Amer Med Assoc. 2004;291(3):317-324.

148. Toggas SM, Masliah E, Mucke L. Prevention of HIV-1 gp120-induced neuronal damage in the central nervous system of transgenic mice by the NMDA receptor antagonist memantine. Brain Research. 1996;706(2):303-307.

149. Lipton SA. Memantine prevents HIV coat protein-induced neuronal injury in vitro. Neurology. 1992;42(7):1403-1405.

150. Nath A, Haughey NJ, Jones M, Anderson C, Bell JE, Geiger JD. Synergistic neurotoxicity by human immunodeficiency virus proteins Tat and gp120: protection by memantine. Ann Neurol. 2000;47(2):186-194.

151. Anderson ER, Gendelman HE, Xiong H. Memantine protects hippocampal neuronal function in murine human immunodeficiency virus type 1 encephalitis. J Neurosci. 2004;24(32):7194-7198.

152. Schifitto G, Navia BA, Yiannoutsos CT, et al. Memantine and HIVassociated cognitive impairment: a neuropsychological and proton magnetic resonance spectroscopy study. AIDS (London, England). 2007;21(14):1877-1886.
HIV/AIDS - Research and Palliative Care

\section{Publish your work in this journal}

HIV/AIDS - Research and Palliative Care is an international, peerreviewed open-access journal focusing on advances in research in HIV, its clinical progression and management options including antiviral treatment, palliative care and public healthcare policies to control viral spread. The journal welcomes original research, basic science,

\section{Dovepress}

clinical \& epidemiological studies, reviews \& evaluations, expert opinion \& commentary, case reports \& extended reports. The manuscript management system is completely online and includes a very quick and fair peer-review system. Visit http://www.dovepress.com/ testimonials.php to read real quotes from published authors. 